\title{
Metformin İlişkili Laktik Asidoz; Bir Olgu Nedeni ile Literatürün Gözden Geçirilmesi
}

\author{
Bedih BALKAN', Güray DEMIR², Fevzi BALKAN', \\ Halil ÇETINGÖK ${ }^{1}$, Erdal ATİÇ ${ }^{2}$
}

Öz

Metformin biguanid sınıfından, Tip 2 diyabetiklerde, özellikle böbrek fonksiyonları normal hastalarda ilk basamakta kullanılan oral antidiyabetiktir. Metforminin en ciddi ve ölümcül yan etkisi laktik asidozdur. Böbrek yetersizliği laktat atılım bozukluğunun en sık sebebidir. Acil serviste, suisid amaçlı ilaç alımından sonra yüksek anyon açıklı metabolik asidoz varlığı olan hastalarda metformin intoksikasyonu düşünülmelidir. 44 yaşında kadın hasta intihar amaçlı 50 gram metformin alımından 3 saat sonra acil servise bulantı ve karında şişkinlik şikâyeti ile başvurdu. Hastada metformin ilişkili laktik asidoz $(\mathrm{pH}<7.35$, laktat düzeyi $>5 \mathrm{mmol} / \mathrm{L}$ ve bikarbonat $<22 \mathrm{mmol} / \mathrm{L}$ ) tanımlandı. Erken tanı ve hemodiyaliz veya hemofiltrasyon yöntemleri ile metabolik asidozun hızlı düzeltilmesi, destek tedavisi ve kan glikoz düzeyinin ayarlanması pozitif sonuçlara neden olacaktır.

Anahtar Kelimeler: Metformin, Laktik asidoz, Hemodiyafiltrasyon

\section{Metformin Associated Lactic Acidosis; Report of a Case and Literature Review}

\begin{abstract}
Metformin is a biguanide used in the treatment of type 2 diabetic patients with normal renal function. Lactic acidosis is the most serious side effect of metformin. Renal failure is the most common cause of reduced lactate excretion. Metformin intoxication should be suspected when patients presented by high anion gap metabolic acidosis after suicide attempt by ingesting drugs. A 44 years- old healthy women ingested 50 gram of metformin in suicide attempt after 3 hours; she was admiddet to hospital with nause, abdominal discomfort. Patient is defined metformin associate lactic acidosis $(\mathrm{pH}<7.35$, lactate of greater than $5 \mathrm{mmol} / \mathrm{L}$ and bicarbonate of less than $22 \mathrm{mmol} / \mathrm{L}$ ) occurring in a patient. Early diagnosis and rapid correction of metabolic acidosis using hemodialysis or hemofiltration, supportive therapy and maintenance of blood glucose provide the possibility of a positive outcome.
\end{abstract}

Keywords: Metformin, Lactic acidosis, Hemodiafiltration

\footnotetext{
${ }^{1}$ Bakırköy Dr. Sadi Konuk Eğitim ve Araştırma Hastanesi

${ }^{2}$ İstanbul Aydın Üniversitesi Sağlık Uygulama ve Araştırma Merkezi

Yazışma adresi: Dr. Güray DEMİR, İstanbul Aydın Üniversitesi Sağlık Uygulama ve Araştırma Merkezi, Anestezi ve Reanimasyon Kliniği, İstanbul, Türkiye. Tel: +902129795000-5656 E-mail: guraydemir@aydin.edu.tr ORCID ID: 0000-0001-5528-3237.

Geliş Tarihi: 16 Eylül 2019 Kabul Tarihi: 16 Aralık 2019

Doi num: 10.17932/IAU.TFK.2018.008/2020.301/tfk_v03i1007
} 


\section{Giriş}

Metformin, tip 2 Diabetes Mellitus'un (DM) tedavisinde kullanılan, biguanid grubu insülin duyarlaştırıcı bir ilaçtır. Metforminin glikoz düşürücü etkisi başlıca azalmış hepatik glikoz çıkışı (primer olarak glikoneojenezin ve daha az olarak da glikojenolizin inhibisyonu yoluyla), iskelet kasında ve adipositlerde artmış insülin aracılı glikoz alımı ile ortaya çıkmaktadır. $\mathrm{Bu}$ etkilerine ek olarak intestinal glikoz emilimini de azaltmaktadır. Metformin diyabetin tedavisinde tek başına kullanılabileceği gibi kombine tedavilerin içinde de yer alabilmektedir. Kombine edilebileceği ilaçlar; sülfonilüreler, insülin, alfa-glikozidaz inhibitörleri, tiazolidinedionlar, DPP-4 inhibitörleri ve sülfonilüre olmayan insülin salgılatıcılarıdır. Yan etkileri genellikle bulantı, anoreksi, diyare ve/veya abdominal kramplar gibi gastrointestinal yakınmalardır ve hastaların \%50'sinden fazlasında ortaya çıkar. Nadiren ağızda metalik tat olabilir (1). Metforminin bilinen en önemli yan etkisi laktik asidozdur ve mortalite oranları yüksektir, kreatinin seviyesi $>1.4 \mathrm{mg} / \mathrm{dL}$ olanlarda kullanılmamalıdır (2). Laktik asidoz tip A ve tip B olarak iki gruba ayrılır. İlk grup daha sık görülür ve doku perfüzyonu bozuk hastalarda, hipoksi varken veya yokken oluşabilir. Tip B laktik asidoz ise bazı ilaçlara, kimyasallara veya toksik bileşenlere veya laktat birikimine sebep olabilen genetik bozukluklara bağ $l_{1}$ oluşur. Tip B laktik asidoz oluşturan sebeplerden birisi de metformin olarak bildirilmiştir (3). Metforminin laktik asidoza yol açma mekanizması tam belli değildir. Pirüvat dehidrojenaz aktivitesini ve tüketilen ajanların mitokondrial transportunu azaltır, böylece anaerobik metabolizmayı arttırır. Metformin ilişkili laktik asidoz iskelet kaslarından değil ekstrahepatik splanknik yataktan kaynaklanır ve bu nedenle "tip B laktik asidoz" (örneğin; artmış laktat yapımı ile) olarak adlandırılır $(4,5)$.

\section{Olgu}

44 yaşında kadın hasta acil servisimize bulantı, karında şişkinlik, bilinç bulanıklığı, solunum güçlüğü nedeni ile başvurdu. Hastanın hikâyesinde
3 yıldır Tip 2 Diabetes Mellitus nedeni ile metformin 1000 mg 2x1 kullandığı ve 3 saat önce intihar amaçlı 50 adet $1000 \mathrm{mg}$ metformin içeren tableti aldıktan sonra bulantı, karında şişlik, bilinç bulanıklığı ve uykuya meyil oluştuğu için acil servise getirildiği ifade edildi. Acil servisteki muayenede genel durumu orta, bilinci bulanı, kooperasyon ve oryantasyonu olmayan hastanın arteriyel tansiyonu 90/50 mmHg, nabız 105/dk, zayıf, solunum sayıs1 30/dk, arteriyel kan gazında asidoz tespit edilmesi, solunum zorluğu ve Kussmaul solunumu olması üzerine yoğun bakım ünitesine alınarak endotrakeal entübasyon uyguland 1 ve mekanik ventilasyona başlandi. Entübasyon öncesi glaskow koma skoru E2-M4-V2 (gözler açık uyaran ile açılmakta, ekstremitelerde ağrılı uyaran ile çekme yanıtı, anlamsız sesler çıkarmak şeklinde verbal yanıt) idi. Kan gazında $\mathrm{pH}: 6.94, \mathrm{HCO}_{3}: 7.6 \mathrm{mmol} / \mathrm{L}, \mathrm{pCO}_{2}$ : $24.7 \mathrm{mmHg}$, baz açı̆̆ı: $-25.5 \mathrm{mmol} / \mathrm{L}$ iken laktat düzeyi: $12.5 \mathrm{mmol} / \mathrm{L}(0.4-2.2)$ olarak saptand. $\mathrm{Hb}$ : $12.7 \mathrm{~g} / \mathrm{dL}$, lökosit: $11400 \mathrm{~mm}^{3}$, trombosit: 379000 $\mathrm{mm}^{3}$, üre: $27 \mathrm{mg} / \mathrm{dL}$, kreatinin: $0.84 \mathrm{mg} / \mathrm{dL}$, sodyum: $134 \mathrm{mEq} / \mathrm{L}$, potasyum: $4.49 \mathrm{mEq} / \mathrm{L}$, glikoz: $75 \mathrm{mg} /$ dL, ALT: $25 \mathrm{U} / \mathrm{L}, \mathrm{AST}: 35 \mathrm{U} / \mathrm{L}$ olarak tespit edildi. Hastaya sağ juguler santral venöz diyaliz kateteri takıldı. Hipotansiyon gelişmesi nedeniyle dopamin tedavisi başlandı ve hastanın hemodinamik olarak stabil olmadığından laktik asidoz tedavisi amaçlı $120 \mathrm{~mL} /$ dak olacak şekilde devamlı venö-venöz hemodiyafiltrasyon uygulaması başlandı. İlk hemodiyafiltrasyon işlemi 24 (yirmidört) saat süreyle diyaliz sıvısı kullanılarak gerçekleștirildi. Hasta entübasyondan 24 saat sonra ekstübe edildi. Takiplerinde kan gazında asidozu düzeldi, laktat düzeyi düştü ve $\mathrm{pH}$ seviyesi normale geldi. Hasta yatışının dördüncü gününde $\mathrm{pH}: 7.39, \mathrm{HCO} 3-$ : $24.9 \mathrm{mmol} / \mathrm{L}, \mathrm{pCO} 2: 43.4 \mathrm{mmHg}$, baz açığı: $-1.8 \mathrm{mmol} / \mathrm{L}$, laktat:1.6 mmol/L ve genel durumu iyi olunca yoğun bakımdan çıkarıldı. Hastanın vital bulguları, kan şekeri ve laktat düzeyleri stabilize edildikten sonra hastanın tedavisi yeniden düzenlenerek yatışının altıncı gününde taburcu edildi. 
Tablo 1. Hastanın Kan Gazında Tedavi Süresince Değişiklikler

\begin{tabular}{lccccccc}
\hline & Acil & $\begin{array}{c}\text { HDF } \\
\text { öncesi }\end{array}$ & $\begin{array}{c}\text { HDF } \\
\text { 3. saat }\end{array}$ & $\begin{array}{c}\text { HDF } \\
\text { 12. saat }\end{array}$ & $\begin{array}{c}\text { HDF } \\
\text { 24. saat }\end{array}$ & 3.gün & Taburcu \\
\hline pH & 7.26 & 6.94 & 7.09 & 7.40 & 7.49 & 7.46 & 7.39 \\
\hline Laktat $(\mathrm{mmol} / \mathrm{L})$ & 11.5 & 12.5 & 13.7 & 8 & 2.4 & 2.2 & 1.6 \\
\hline $\begin{array}{l}\text { Anyon Açı̆̆ } \\
(\mathrm{mmol} / \mathrm{L})\end{array}$ & -15 & -25.5 & -21.4 & -3.1 & 2.5 & 2 & 1.5 \\
\hline $\mathbf{H C O}_{3}^{-}(\mathrm{mmol} / \mathrm{L})$ & 13.2 & 7.6 & 9.5 & 21.8 & 26.6 & 25 & 24.9 \\
\hline
\end{tabular}

HDF: Hemodiyafiltrasyon

\section{Tartışma}

Kronik kullanımda metforminin laktik asidoza neden olma etkisi 100.000 hastada 3-9 arasında bulunmuştur (6). Son yıllarda yapılan bir çalışmada metformin kullananlarda laktik asidoz siklığ 100.000 hastada 47 olarak bulunmuş önceki literatüre göre sıklığı 5-16 kat daha yüksek tespit edilmiştir (7). Metformin kan konsantrasyon düzeyi ve laktat düzeyi MALA'da erken mortalitede belirleyici olmayabilir. Metformin böbreklerden hem glomerül filtrasyonu hem de tubüler sekresyon yoluyla değiştirilmeden atılır (8). Yapılan çalışmalar sonucunda, laktat düzeyinin ve serum metformin düzeyinin prognostik değerinin olmadığı belirtilmiştir (9). Laktik asidozun prognozu oldukça kötüdür. Serum laktat düzeyi $5 \mathrm{mmol} / \mathrm{L}$ olanlarda mortalite $\% 75$ olup; laktat düzeyi $10 \mathrm{mmol} / \mathrm{L}$ ulaştığında yaşam şansı yok denecek kadar azdır. Laktik asidoza sahip 126 hastada yapılan bir çalışmada median sağ kalım süresi 38.5 saat olarak belirlenmiş 30 günlük yaşam süresi \%17'dir. Başka bir çalışmada metformin tedavisi sonrasında laktik asidoz gelişenlerde, laktat düzeyi $13.1 \mathrm{mmol} / \mathrm{L}$ üzerinde olanlarda ölüm oran1 $\% 45$ olarak gerçekleşmiştir $(8,10)$. Literatürün gözden geçirildiği başka bir çalışmada, $\mathrm{pH}<6.9$ altında ve laktat konsantrasyonu $25 \mathrm{mmol} / \mathrm{L}$ üzerindeki vakalarda mortalite oran $1 \% 83$ olarak tespit edilmiştir. Metformin konsantrasyonu $50 \mu \mathrm{g} /$ $\mathrm{mL}$ olanların \%38'inde mortalite ile seyretmiştir (11). 722 olgunun incelendiği başka bir çalışmada 2000'li yıllardan sonraki vakalarda mortalite oranı \%25 olarak rapor edilmiştir (12). İtalya'da yapılan bir çalışmada mortalite oranı \%25.4 olarak hesaplanmıştır (13). Olgumuzda kan pH 6.94 seviyesine inip laktat düzeyi $13.7 \mathrm{mmol} / \mathrm{L}$ 'ye kadar çıtı. Ancak erken ve etkili hemodiyafiltrasyon girişimi sayesinde laktat düzeyleri ve kan gazı değişkenleri normale geldi. Hastanın yoğun bakımdan çıktığında $\mathrm{pH}: 7.39$, laktat: $1.6 \mathrm{mmol} / \mathrm{L}$ olarak tespit edildi.

Metforminin hipoglisemik yan etkisi diğer ağızdan alınan antidiyabetiklerle beraber kullanılınca ortaya çıkabilir. Ayrıca aşırı doz metformin kullanımında hipoglisemi gelişebilir. $\mathrm{Bu}$ nedenle aşırı doz metformin kullanımı ile başvuran olgularda hipoglisemiye dikkat edilmelidir. Olgumuzda takiplerinde hipoglisemi gözlenmemiştir.

Metformine bağlı laktik asidozda bikarbonat tedavisi tartışmalıdır, bu amaçla sıklıkla uygulanan yöntemler parenteral $\mathrm{NaHCO}_{3}, \mathrm{HCO}_{3}^{--}{ }^{-c} l_{1}$ devaml venövenöz hemodiyafiltrasyon (CVVHF) ve aralıklı hemodiyalizdir (14-18). Hemodiyaliz tedavisini hemodinamik olarak tolere edemeyen hastalarda hemofiltrasyon tedavisi önerilmiştir (17). Sağ kalım, erken dönemde başlanan CVVHF veya hemodiyaliz ile tedavi edilen hastalarda daha yüksek düzeydedir. Yapılan çalışmalarda; bikarbonatlı sürekli venövenöz hemofiltrasyon ile laktatlı sürekli hemofiltrasyon karşılaştırılmış bikarbonatlı tedavinin asidozu düzeltmede daha etkili olduğu görülmüştür (19). Thomas ve arkadaşlarının yaptığı çalışmada ise bikarbonat ve laktatlı replasman sivıları kullanılarak yapılan sürekli venövenöz hemofiltrasyonda herhangi bir farklılık saptanmamıştır. Mortalite oranları her iki grupta aynıdır (20). Sürekli venövenöz hemofiltrasyonun laktat klirensi üzerine olan etkisi 
\%3'ün altında görünmektedir (21). Literatürde sunulan bir olguda metabolik asidozu derin $(\mathrm{pH}$ : 6.87, HCO3-: $3 \mathrm{mmol} / \mathrm{L}$, laktat: $15 \mathrm{mmol} / \mathrm{L}$ ) olguda da intravenöz (IV) sıvı ve $\mathrm{NaHCO}_{3}$ ile birlikte yapılan bikarbonatlı HD (hemodiyaliz) ile hızlı iyileşme sağlanmış ve mükemmel sonuç alınmıştır (22). Erken evrede venövenöz hemodiyafiltrasyonla başarılı sonuçlar alınmış vakalar vardır $(23,24)$. Bizim olgumuzda $\mathrm{pH}$ değeri 6.94 seviyesi, laktat $13.7 \mathrm{mmol} / \mathrm{L}$ üzerinde olmasına rağmen erken etkili hemodiyafiltrasyon ile hastanın değerleri düzelmiştir. Laktik asidoz tedavisinde IV sodyum bikarbonat $\left(\mathrm{NaHCO}_{3}\right)$ kullanımı tartışmalıdır. Eğer ağır asidoz varsa $(\mathrm{pH}<7.1)$ uygulanabilmektedir, fakat teorik olarak dezavantajları vardır (25). Bu dezavantajlar arasinda hemoglobin disosiasyon eğrisinin sola kayması, rebound metabolik alkaloz, serum potasyum ve kalsiyum dağılımında değişimler, sodyum yüklenmesi, miyokard kontraktilitesinde azalma, karbondioksit üretiminde artış ve bolus enjeksiyonlardan sonra oluşan refleks vazodilatasyon sayılabilir (26). Bizim vakamızda $\mathrm{pH}$ 6.94 olmasına rağmen dezavantajları düşünülerek hastaya sodyum bikarbonat tedavisi yapılmadı. Hemodiyaliz, sürekli venövenöz hemodiafiltrasyon, dikloroasetat veya sodyum bikarbonat infüzyonları metformin ile ilişkili laktik asidozda tedavinin bir parçası olarak kabul edilmektedir (27). Erken hemodiyaliz ve hemofiltrasyon tedavisi ile metformin elimine edilmekte, yüz güldürücü sonuçlar alınabilmektedir (28). Yayınlanan bir vakada uzun diyaliz süresinin metformin ilişkili laktik asidozda faydalı olabileceği ifade edilmiştir (29). Sonuç olarak özellikle insülin direnci üzerine olumlu etkileri nedeniyle tip 2 DM tedavisinde tek veya kombine olarak kullanılabilen metformin, laktik asidoz gibi bir yan etki potansiyeline sahiptir. Oldukça nadir, önlenebilir bir yan etki olmakla birlikte, hasta seçimi iyi yapılmadığı zaman mortal bir yan etki olabilmektedir. Bu nedenle ileri yaşta, ciddi diyabetik komplikasyonları bulunan tip 2 diyabetlilerde tercih edilmemesini öneriyoruz. $\mathrm{Bu}$ vakada özellikle laktik asidoz ve onun olumsuz etkilerine dikkat çekilmek istenmiş, yüksek mortalite ile seyreden bir klinik tablo etkili olarak tedavi edilmiștir.

\section{KAYNAKLAR}

1. American Diabetes Association. Standards of medical care in diabetes-2013. Diabetes Care 2013; 36(1): 11-66.

2. Lalau JD. Lactic acidosis induced by metformin: incidence, management and prevention. Drug Saf 2010; 33(9): 727-40.

3. Ahmad S, Beckett M. Recovery from ph 6.38: Lactic acidosis by hypothermia. Emerg Med J 2002; 19: 169-71.

4. Orban JC, Giunti C, Levraut J et al. L'acidose lactique reste une complication grave $\mathrm{du}$ traitement par metformine metformin-associated lactic acidosis remains a serious complication of metformin therapy. Ann Fr Anesth Reanim 2003; 22: $461-5$.

5. Bailey CJ, Wilcock C, Day C. Effect of metformin on glucose metabolism in the splanchic bed. $\mathrm{Br} \mathrm{J}$ Pharmacol 1992; 105: 1009-13.

6. Stang M, Wysowski DK, Butler-Jones D. Incidence of lactic acidosis in metformin users. Diabetes Care 1999; 22(6): 925-7.

7. Van Berlo-van de Laar IR, Vermeij CG, Doorenbos CJ. Metformin associated lactic acidosis: incidence and clinical correlation with metformin serum concentration measurements. J Clin Pharm Ther 2011; 36(3): 376-82.

8. Vecchio S, Giampreti A, Petrolini VM et al. Metformin accumulation: lactic acidosis and high plasmatic metformin levels in a retrospective case series of 66 patients on chronic therapy. Clin Toxicol (Phila) 2014; 52(2): 129-35.

9. Kajbaf F, Lalau JD. The prognostic value of blood $\mathrm{pH}$ and lactate and metformin concentrations in severe metformin-associated lactic acidosis. BMC Pharmacol Toxicol 2013; 14: 22.

10. Stacpoole PW, Wright EC, Baumgartner TG et al. Natural history and course of acquired lactic acidosis in adults. DCA-lactic acidosis study group. Am J Med 1994; 97: 47-5414. 
11. Dell'Aglio DM, Perino LJ, Kazzi $Z$ et al. Acute metformin overdose: examining serum $\mathrm{pH}$, lactate level, and metformin concentrations in survivors versus nonsurvivors: a systematic review of the literature. Ann Emerg Med 2009; 54(6): 818-23.

12. Kajbaf F, Lalau JD. Mortality rate in so-called "metformin-associated lactic acidosis": a review of the data since the 1960s. Pharmacoepidemiol Drug Saf 2014; 23(11): 1123-7.

13. Renda F, Mura P, Finco G et al. Metforminassociated lactic acidosis requiring hospitalization. A national 10 year survey and a systematic literature review. Eur Rev Med Pharmacol Sci 2013; 17: 45-9.

14. Lalau JD, Race JM, Brinquin L. Lactic acidosis in metformin therapy. Relationship between plasma metformin concentration and renal function. Diabetes Care. 1998; 21(8): 1366-7.

15. Heaney D, Majid A, Junor B. Bicarbonate haemodialysis as a treatment of metformin overdose. Nephrol Dial Transplant 1997; 12(5): 1046-7.

16. Barrueto F, Meggs WJ, Barchman MJ. Clearance of metformin by hemofiltration in overdose. J Toxicol Clin Toxicol 2002; 40(2): 177-80.

17. Arroyo AM, Walroth TA, Mowry JB, Kao LW. The MALAdy of metformin poisoning: Is CVVH the cure? Am J Ther. 2010; 17(1): 96-00.

18. Panzer U, Kluge S, Kreymann G, Wolf G. Combination of intermittent haemodialysis and the high-volume continous haemofiltration for the treatment of severe metformin-induced lactic acidosis. Nephrol Dial Transplant 2004; 19: 21572158.

19. Fall PJ, Szerlip HM. Lactic acidosis: from sour milk to septic shock. J Intensive Care Med 2005; 20: 255-71.
20. Thomas AN, Guy JM, Kishen $\mathrm{R}$, et al. Comparison of lactate and bicarbonate buffered haemofiltration fluids: use in critically ill patients. Nephrol Dial Transplant 1997; 12: 1212-7.

21. Rachoin JS, Weisberg LS, McFadden CB. Treatment of lactic acidosis: appropriate confusion. J Hosp Med 2010; 5: E1-7.

22. Di Grande A, Vancheri F, Giustolisi V et al. Metformin-induced lactic acidosis in a type 2 diabetic patient with acute renal failure. Clin Ter 2008; 159: 87-89.

23. Bruijstens LA, van Luin M, Buscher-Jungerhans PM, Bosch FH. Reality of severe metformininduced lactic acidosis in the absence of chronic renal impairment. Neth J Med. 2008; 66(5): 185-90.

24. Tay S, Lee IL. Survival after cardiopulmonary arrest with extreme hyperkalaemia and hypothermia in a patient with metformin-associated lactic acidosis. BMJ Case Rep 2012 20; 2012. pii: bcr2012007804.

25. Teale KF, Devine A, Stewart H, Harper NJ. The management of metformin overdose. Anaesthesia 1998; 53: 698-701.

26. Schelling JR, Howard RL, Winter SD, Linas SL. Increased osmolal gap in alcoholic ketoacidosis and lactic acidosis. Ann Intern Med 1990; 113: 580-582.

27. Forsythe SM, Schmidt GA. Sodium Bicarbonate for the Treatment of lactic acidosis. Chest 2000; 117: $260-7$.

28. Baştürk T, Balkan $B$, Aytekin $M$ et al. Lactic Acidosis due to Metformin Overdose. What treatment should be? A Case Report and Review of the Literature. BANTAO Journal 2009; 7 (2): 4446.

29. Rifkin SI, McFarren C, Juvvadi R, Weinstein SS. Prolonged hemodialysis for severe metformin intoxication. Ren Fail 2011; 33(4): 459-61. 